\title{
RITUAL COORDINATION OF MEDICAL PLURALISM IN HIGHLAND NEPAL: IMPLICATIONS FOR POLICY
}

\author{
Barbara Parker \\ University of Michigan, Ann Arbor, MI 48109, U.S.A.
}

\begin{abstract}
In highland Nepal, just as in many other regions of South Asia, multiple indigenous healing traditions and a variety of traditional curing specialists co-exist in a pluralistic cultural environment. It is argued that the interaction of diverse medical traditions is a particular aspect of the more general tendency toward the accretion and super-imposition of cultural traits which has been a common feature of Hindu-influenced social systems. Allopathic medicine and its practitioners, therefore, are less likely to displace traditional curing practices than to become integrated into a network characterized by continued pluralism. To insure that allopathy is properly understood and utilized within the pluralistic context. the identification and training of coordinating personnel who may specialize in diagnosis or referral demonstrates promise. The traditional curing network of the Thakali people of Northwest Nepal is described, with particular attention to the $m u$ tu ceremony of divination. as an example of an indigenous agency of medical referral. It is suggested that referral specialists such as the Buddhist monks who perform $m u t u$ are particularly appropriate targets for health education initiatives aimed at familiarizing village populations with the role and proper usage of modern medicine.
\end{abstract}

Key words-Nepal, pluralism, ritual healers, referrals

\section{INTRODUCTION}

It is generally acknowledged that the acceptance of Western medical concepts and therapeutic techniques by the populations of developing countries is influenced by the presence of indigenous healing systems. Because the human experience (though not interpretation) of illness is a true universal, all societies possess a system of health beliefs and related practices. In certain culture areas of the developing world, these systems have achieved a high degree of sophistication and complexity. Southern Asia is one such case. In many areas of Nepal, for instance, the interaction of Western and indigenous healing systems is complicated by the co-existence of several indigenous traditions [1-4]. This medical pluralism is to some extent pan-South Asian, but it is particularly elaborate in urban areas, in regions which have received a recent influx of immigrants, and in the Hindu-Buddhist interface area near Nepal's northern border. Using illustrative data collected in this interface area, this paper considers two health-care related issues:

1. The strategy of utilizing indigenous Nepalese healers as agents for the introduction of allopathic medicines or methods is currently under debate [5-10]. It is hoped that the involvement of local healers in health care programs will forestall the resistance of these potentially powerful opponents of allopathy, and will help to compensate for the absence of trained medical personnel. In medically pluralistic societies, however, this strategy requires that various indigenous practitioners be assessed and compared, so that the most effective agent may be selected. Presumably this will be the practitioner who is the first or most frequent choice of the consumer of medical services. Durkin-Longley, however, has demonstrated that patterns of resort are by no means easy to establish methodologically, since interview responses are not always consistent with observed patterns of therapeutic usage [2]. Therefore, an alternate basis for selection and recruitment is to be desired.

2. Discussions of patterns of resort invariably carry stated or unstated assumptions regarding the eventual result of the interaction of diverse medical traditions. Differing visions of the health-care futures of the developing nations have emerged from these discussions. Foster, for example, implies that there is generally competition or antagonism between traditional and modern medicine. In his words: "... the evidence is overwhelming that in countries where traditional peoples have had access to modern medicine for a generation or longer, and where this medicine has been of reasonably good quality, the battle has been won, and scientific medicine is the victor" $[11$, p. 304]

The data on medical pluralism from the Nepal hills, however, suggests that such an outcome is not inevitable in that region, or perhaps in any region, of the nation. Stone has found that in central Nepal, although there is some competitiveness in the attitudes of medical doctors and local practitioners, nevertheless, "actual treatments of illnesses reflect a high degree of integration of these systems" [3, p. 78]. What is more, observations of medical pluralism in southern India support the possibility of long-term co-existence of medical traditions in that nation as well $[12,13]$.

It can be argued that the 'replacement' model is not culturally appropriate in an area of the world that has been so pervasively influenced by Hinduism. The 
Hindu religio-social system is renowned for its capacity to absorb incoming beliefs and practices through accretion and hierarchization. Louis Dumont proposes that the cultural history of India is characterized by what he terms the 'extrinsic borrowing' of prestigious foreign cultural elements. He states that "The borrowing assigns a meaning to the element borrowed, and usually the original functional feature does not disappear: the new (prestigious) one is super-imposed on it" $[14$, p. 192].

The super-imposition need not apply the absence of competition between beliefs, practices and/or practitioners. Another possibility is a dynamic system in which these functionally equivalent elements co-exist, but continuously wax and wane in relative influence and persuasive power over long periods of time. Nevertheless, if traditional elements do not disappear, then we should expect that the long-term co-existence of these with introduced elements will require some system of coordination. In the case of co-existing systems of medical practice, this coordination function may be served by systems of referral. From the reference point of the consumer of medical services, systems of referral can unite competing options in a 'metasystem', whose elements interact in an integrated and complementary fashion. South India serves as a case in point.

Nichter [12] reports that in the South Kanara District of India's Karnataka state, a traditional referral network has emerged as a means whereby the multiple aspects of illness can be treated in the context of perceived multiple causation. These networks, many of which include traincd allopaths, frequently revolve around the use of an astrologer as intermediary. When a curer is unsuccessful in treating an illness, he may ask an astrologer to determine what aspects of the condition have been left untreated. In so doing, the astrologer is able to suggest an appropriate source of supplementary treatment to the patient. Data collected by Beals in the Mysore region of Karnataka, however, reveals that specialists are not consulted for diagnosis and referral in the villages studied. Instead, treatment advice is solicited from relatives, neighbors and "authoritative persons within the network of contacts possessed by the family and the village of the patient" $[13$, p. 196]. Further research into the identity of these authoritative individuals, however, might identify a pattern of regularity with regard to the probable age, status and background of those persons likely to be consulted.

It is my contention that the indigenous loci of referral and treatment advice represent the most convenient and effective points for the introduction of information into local South Asian medical "metasystems'. Where systems of referral can be found and their coordinating personnel identified, these individuals may constitute the most suitable targets for policymakers in Western health education. Through indigenous referral systems, information concerning the role and appropriate uses of modern allopathic medicine can be made available to the treatmentseeking population at large.

Initially, however, data collection must be oriented toward determining whether such coordinating personnel exist in a particular local curing network. South Asia is characterized by regional diversity, and the variation in local medical systems is correspondingly great. There may be many in which no such linkages of referral are found. In other cases, the coordinating role may be played by non-specialists, or referrals between curers will be reciprocal. In certain local systems, however, specifically referraloriented persons or functions have emerged; and it is to such cases that this argument primarily refers. As an illustration of a local agency of medical coordination, I will review the ritual coordination of a pluralistic health-care system in highland Nepal.

\section{THE NORTHERN BORDERLANDS: THAK KHOLA}

The data presented here were collected in the course of an 18-month ethnographic study of the Marpha subgroup of the Thakali-speaking peoples of northwestern Nepal. During the pre-modern era. Thak Khola was a tributary hinterland to various Tibetan and Indian kingdoms. It was incorporated into a modern nation state only after the Gurkha unification of Nepal in the late eighteenth century. Influences from both the Indian and the Tibetan culture areas have been present for centuries, however, in conjunction with purely local beliefs and practices $[15,16]$. The religious tradition of the region therefore includes elements of Tibetan Buddhism and Bonpo, local animism and (particularly in the southern Thak) Hinduism. Each of these traditions constitutes an internally consistent system of thought concerning the nature and composition of the humanly relevant universe. Nevertheless, these religious traditions are not mutually exclusive. There is considerable overlap in so far as each has incorporated elements of thought and practice from the others. What is more, the salience to villagers of the Hindu, the Buddhist, and the purely local ritual systems (plus, more recently, the Western-scientific medical system) has varied throughout a history of interaction. A brief outline of local history reveals, however, that while the strength of each tradition has varied in relation to the others, none has yet replaced the alternatives.

The speakers of Thakali, a Tibeto-Burman language, are numerically and economically dominant in upper Thak Khola, although the area is also inhabited by members of the Nepali-speaking occupational castes who have immigrated in search of jobs, and by a few Tibetan-speakers from the North. Thak Khola is renowned as one of Nepal's busiest Himalayan trade routes. In addition to agriculture and pastoralism, the Thakali have always engaged in some trade and commerce. During the late nineteenth century, however, the government of Nepal granted the southern Thakalis a local monopoly on the lucrative salt trade from Tibet. This political boon, which was abolished only in 1928, garnered them considerable wealth as well as political dominance in the region. These economic and political developments had significant impact upon the religious profile of Thak Khola.

Prior to the Gurkha unification, Tibet was the dominant cultural force in the area $[17,18]$. Tibetan Buddhism and Bonpo were well established there by the end of the medieval period, and while purely local gods and spirits were propitiated, the 
introduced Tibetan cultural elements were the prestige forms which were emulated by local elites. With the Gurkha unification, however, the hegemonic winds abruptly changed. The southern Thakali elites were quick to perceive that they could not establish an advantageous relationship with the new national political elite unless their group conspicuously adopted certain Hindu practices. This entailed the discouragement of traditional practices associated with Tibetan Buddhist culture, which the Gurkhas held in low esteem. Therefore, the urbanized Thakali elites launched a 'Hinduization' campaign, in which they attempted to establish themselves as high-caste Hindus of the Thakuri caste. This campaign had but limited success, in that they did not achieve Thakuri standing. Moreover, there is evidence that even among the southern Thakali, this campaign was resisted by many less prosperous families who remained in their home villages [19].

The northern Thakali-speakers, who did not receive benefits from the trade monopoly, were not significantly Hinduized in their religious beliefs in this or any period (although they are now attempting to emulate prestigious Nepali dress and language forms). Nevertheless, there are reports from many Thak Khola villages which suggest that shamanic revitalization movements (associated by many Thakalis with curing systems in the Hindu lowlands) took place earlier in the twentieth century $[20,21]$. The Marpha subgroup, however, appears to be currently undergoing a type of 'Buddhist rationalization' [22], wherein the propitiation of purely local gods by shamanic practitioners is losing prestige in relation to ceremonies featuring the chanting of texts by Buddhist monks. This suggests that a new religious strategy may be taking shape in the area, perhaps as a consequence of the southern Thakalis' failure to secure the twice-born status they had sought through Hinduization.

This brief overview reveals that no easy summary of religious trends in Thak Khola is possible. The various strands of tradition wax and wane in relative strength, at least partly in response to external pressures and changing socio-economic conditions. Once a particular tradition has been successfully introduced, however, it tends to retain an active role in the local religious repertoire for centuries. To suggest that changes in the relative popularity of two alternative religious systems implies replacement of one by the other. then, is to take a short-term view of the nature of change in Thak Khola. As history demonstrates, traditions which fade into relative obscurity in one century may surge into the foreground once again in another. Pluralism, therefore, does not necessarily entail a static structure in which all elements co-exist in perfectly balanced harmony. Instead, various ritual elements represent alternative interests and viewpoints which interact within an open, complex and, above all, fluid system of belief and behavior

The focus of this essay is upon the means by which these alternative traditions, together with introduced scientific medical terms and treatments, form a coherent system in the domain of health and healing. Each tradition includes an explanation of the ills that plague humanity and the measures that are required to restore well-being. Attached to each, in other words, is a set of health-related beliefs and a system of medical practice. Maru [23] suggests that, based on the experience of the Chinese, indigenous curing practices may be integrated with introduced allopathic ones even when the two theoretical systems remain incongruent. Among the Thakali, contradictions in alternative systems of health beliefs are indeed bridged at the level of behavior, through ritual coordination of healing alternatives.

The elements that are ritually coordinated are not elements of belief, but are elements of practice associated with traditions of curing expertise. Specific illness beliefs derived from different sources co-exist primarily by means of compartmentalization within the encompassing logic of a more general worldview. In the most general terms, the Thakali tend to view misfortunes (including illness) as either a problem with balance/imbalance, as the escape of some essential component of well-being, or as attack and invasion by some supernatural entity. In the case of illness, these events may be linked, such as when sudden loss of the la (Thk.), a vital component of the patient's spirit, leaves an imbalance in the self-system which renders it more than usually vulnerable to attack by demons (dhui, Thk.) or witches ( $p u$ mi sha, Thk.). The fact that these entities are motivated less often by malice than by envy or by a greedy desire to consume suggests that the social meaning of illness in this commercially-oriented culture involves some cultural concern with potential wealth disparities.

Within this general framework, however, there are several health systems which Thakalis turn to for the explanation of specific episodes of illness and for indication of appropriate cures. From these systems, the following categories of curing personnel have emerged:

\section{Aamchi}

The aamchi is the traditional practitioner of Tibetan herbal medicine, which resembles the Indian Ayurvedic medical system in some respects and Chinese medical traditions in others. He is a Buddhist monk who has undergone a long period of study under a teacher. The average village aamchi, however, relies on a religious text, written in classical Tibetan, which contains instructions for the treatment of each disorder. His primary method of diagnosis is measuring the distance between the pulses in the wrist. These are in three locations-in the skin, the muscle and the bone. He also inspects the patient's urine and skin color. This is especially helpful in diagnosing liver disease. It is said that the liver sometimes 'boils over', and its contents spill out into the rest of the body. This is an indication that the affliction is a 'hot' disease. A common cause of disease is that the body becomes 'hot' or 'cold', often from eating an excessively 'hot' or 'cold' diet. A hot body is treated with foods or herbs that are intrinsically cold, and vice versa. Usually medicine (a combination of herbs) is given orally, but sometimes blood is let from the veins. In rare cases, herbs are placed upon the skin at strategic spots on the body (saang, Thk.) and ignited. 


\section{Lama and dawa (Buddhist monks)}

Monks are called upon to perform ceremonies of exorcism or appeasement if the affliction is deemed to be caused by a supernatural agent. They usually treat these afflictions by performing a combination of rites, gyep shi (for a more complete description see [24] and lalu $[22,25]$ ), in which dhui are lured away from the victim and his or her $l a$ is summoned to return. Either married monks (dawa) or celibate gelong lama may perform these rites. Celibate gelong lama, however, also perform chi lap, a blessing ceremony which neutralizes pollution offenses against local divinities. The divinities most sensitive to pollution offenses are the $l u$ who reside in watercourses, under the ground, and in the altar rooms (tin tang, Thk.) of many Thakali homes. Lu may cause insanity or skin eruptions when offended, or they may retard the healing of wounds. If $l u$ are the suspected agent of disease, the lama may instruct the sufferer to burn sweet-smelling incense in the home, since the $l u$ experience a foul smell as pollution. If this does not avail, a chi lap will be commissioned.

\section{Ayalama or dhom}

Local legends point to a correspondence of the ayalama with priests of the Tibetan Bonpo tradition, but the Thakali ayalama is an indigenous institution to the extent that these practitioners are recruited through hereditary affiliation with certain kin groups $[16,26]$. Specific lineages transmit the requisite knowledge (usually unwritten mantra, or sacred utterances) through apprenticeship training. The ayalama do not undergo possession trance, and in the Marpha area they are not usually called upon to cure specific episodes of illness. However, they are called on to render preventive services by routinely offering sacrificial animals to local dieties (hla, Thk.) who would otherwise cause affliction. In addition, if several villagers have become ill after visiting or working near a site sacred to a particular hla, these specialists are sometimes called to that site to perform a ceremony of propitiation on behalf of the village. The expected outcome of the rite is that the afflicted will be spared and that no additional victims will be attacked

\section{Jhankri (shaman) [27]}

This possession-type shamanistic curing system is a common feature of Nepal's Hindu lowlands, and its penetration into the northern border areas reveals Hindu influence upon these regions. Jhankri do not play a prominent role in upper Thak Khola at present, however, perhaps because the Hinduization campaigns of the salt monopoly era have lost momentum in the last two decades. The jhankri is distinguished from the ayalama on the basis that the former experiences a trance state during the healing ceremony, and he does not inherit access to curing mantra through descent. Instead, he is recruited by a jhankri god. This god initiates the shaman by striking him with a coma-like swoon, which may endure for weeks. During this time (at the cost of great personal danger) the initiate is instructed with the healing mantras.

In modern times the Marpha Thakali themselves rarely becomc jhankri. This role is now filled primarily by members of occupational castes (Damai and $\mathrm{Kami}$ ) who are resident in the area. Because occupational caste members are thought to be too ritually low to enter Thakali homes, however, jhankri are called upon less often now than in the past, when there were celebrated Thakali-speaking jhankri who could be called. Nevertheless, they are the standard recourse when attack by $p u m i$ sha is the suspected cause of the affliction. A jhankri must then be called to do battle with the witch. This is sometimes done by heating a metal rice scoop until it becomes red-hot and applying it to the tongue of the patient. The patient is not burned because he/she is protected by the jhankri's mantra. The witch, who is not so protected, will be burned, and, hopefully, forced thereby to relinquish her attack on the patient.

\section{Western medicine}

Village Thakalis often travel to Pokhara, Kathmandu or other areas where pharmacies are common, but they also have two points of contact with allopathic medicine in Thak Khola itself. The district center at Jomson contains a government health post, and, since the early 1980 s, there has been a small pharmacy nearby. The pharmacy is privately owned by a Thakali-speaker of Marpha, who has been educated as a pharmacist. He is therefore trusted by many local people to act as a diagnostician and to prescribe one of the remedies he is offering for sale. Not everyone in the area can afford his remedies, but the Thakali themselves are wealthier than most Nepalese hill peoples. The village health post is also used, but less often. It is beset by the usual problems that plague such remote medical outposts such as a severe shortage of drugs and supplies.

\section{THE INTERACTION OF TRADITIONS}

Upon review of this long list of disease systems and curing personnel, an immediate question arises. How do villagers determine which system of explanation is relevant to a particular disease episode, and which practitioner or remedy can be expected to restore them to health? Some individuals begin by trying home remedies, or they may try to persuade a passing trekker to donate antibiotics. The pharmacist is also asked for advice by some villagers. This immediate recourse to allopathic medicine may be increasing as Thakali youth become better educated in the Western tradition.

Not even the most highly educated villagers, however, have abandoned the use of traditional curers. It is generally acknowledged that Western medicine is not the proper remedy for every affliction. The Thakali do not, for example, divide illnesses neatly into the Cartesian 'physical' and 'mental' categories; and a single agent (such as the $l u$ ) may cause illnesses of both types. Furthermore, nightmares, insomnia, emotional disturbance and general bad luck do not yield to treatment by the pharmacist, while they seem to be treated effectively enough by traditional practitioners to warrant continued use of their services.

What is more problematic from the point of view of the introduction of health care services is the fact that local people possess an imperfect understanding of the most appropriate uses of Western medicine. 
For example, it is commonly believed that allopathic cures are quick but of short duration, while traditional medical cures are slow but final (a belief identified by Burghart [28] as a general characteristic of South Asian constructions of 'English' medicine). What is more, it is commonly held that Western medicine is appropriate for adults but is contraindicated for children. Informants attributed this conviction to the belief that Western medicine damages the teeth of infants and small children. Even high-school graduates seemed unaware of the fact that this is true only of tetracycline (a drug frequently carried by passing trekkers and hence common in the area). Instead, this is identified as a general property of allopathic medicine in the understanding of village residents. As a result, the age group that is most vulnerable to the effects of infectious and parasitic diseases is frequently denied access to effective emergency treatment through antibiotics and antiparasitics.

When attempts at self-diagnosis and treatment prove ineffective, or when a particularly alarming or perplexing condition afflicts a family member, the family does not attempt to choose among the many healing alternatives available to them. Instead, they approach a lama or a dawa and request the performance of a divination called $m u t u$. They may select a particularly well-known or powerful gelong lama for the performance, but many households maintain a close relationship (called chin ta, Thk.) with a specific monk who knows them intimately. If so, then this is the individual they are most likely to approach. Often, it is said, there is no need to describe the problem to the monk or even to identify the victim. It may be enough to say 'please do $m u$ tu for us', and to set a quantity of grain before the monk as an offering. He should perceive at once what is wrong and who is affected.

The technical portion of $m u t u$ is the consultation of a divination board whose positions represent the Tibetan 12-yr calendrical cycle. Each year is conventionally associated with a familiar animal, whose essential nature summarizes certain metaphysical, psychological, and cognitive aspects of being. The monk tosses a set of dice and, beginning with the square representing the patient's birth year (lar ta, Thk.) animal, he advances as many squares upon the board as the toss indicates. The properties of the lar $t a$ upon which he finally lands will be a clue to the nature and cause of the affliction; and when the cause is known, the treatment requirements follow logically. There is, however, a great deal of latitude for interpretation by the monk. In the final analysis, therefore, it is thought to be the monk's own powers of extraordinary perception that assure an accurate diagnosis and referral. By dint of meditation and the performance of austerities, he has attained a 'pure mind' and a 'power to know' that exceeds the understanding of ordinary persons.

Once he has ascertained the nature of the problem, the monk recommends that a particular medical system and a particular practitioner be consulted for a cure. In some cases he himself will offer to perform a gyepshi-lalu or a chi lap, but if he deems these measures inappropriate he may refer the patient to another monk (such as the aamchi), to a jhankri, or to allopathic medicine [29]. If Western medicine is the recommendation, it is said that he will even identify the best sourcc to consult: usually the Jomson pharmacy or the health post will be named, unless the $m u$ tu takes place among emigrants or travellers to the urban areas, where the choice is wider. Informants report that once the referral has been rendered, the patient is already on the road to recovery, because he believes in the lama or dawa, and feels happy, hopeful and confident of a successful outcome.

It should be noted, however, that $m u t u$ diagnosis is not always unambiguous or peremptory in tone. In fact, it may be highly complex and interactional, requiring the participation of afflicted persons and their families. For example, when a middle-aged village woman was suddenly stricken unconscious, her family appealed to its monk for $m u t u$. She was divined to be suffering from either a tip (pollution offense to a deity) or a stroke. The family did not really know the cause of a 'stroke', however, and the anthropologist was called upon for an explanation which the monks did not satisfactorily provide. Meanwhile, the family recalled that the victim had recently singed a goat skin at the cooking fire. Since such an act pollutes the family hearth and releases an odor that is particularly offensive to $l u$, a chi lap was commissioned. When the victim failed to improve at once, however, it was assumed that the alternative diagnosis had been confirmed. Since 'stroke' was known to be a diagnosis consistent with allopathic medicine, the family was advised to seek out the 'doctor' (pharmacist). He could offer no cure, however, and the patient died within a few days. Later, villagers were overheard describing the case as an unavoidable death diagnosed by the monks as stroke.

This example suggests a number of points. First, it illustrates that local understanding of Westernscientific disease categories is indeed incomplete. It does, however, indicate a willingness to draw these categories into the local system of medical explanation, diagnosis and referral. In short, it reflects a potential for the introduction of allopathic health information at this juncture in the treatment-seeking process. Equally, however, it supports the contention that Western medical categories are not viewed as elements of a model which is antithetical to traditional models. Instead, these categories are elements of a larger system of interacting possibilities.

\section{IMPLICATIONS FOR POLICY}

The variety of local healers and systems of curing found in and around Marpha presents a barrier to the easy prediction of care-seeking behavior on the part of the village population. It is logical to assume that villagers will shop for a cure in difficult cases and, if one is not immediately achieved, that multiple use patterns will prevail (and indeed this is generally the case). This practice, combined with the consultation of a $m u$ tu practitioner who is well-known to the family, supports the supposition that patterns of consultation are guided by both pragmatism and familiarity.

The institution of $m u t u$ is not primarily therapeutic, however. Instead, it is a referral system which coordinates the various indigenous and introduced 
medical traditions in Thak Khola. In so doing, it brings some measure of order and predictability to the process of therapeutic selection. It therefore constitutes an appropriate entry-point for accurate information concerning the concepts and applications of the Western medical system. Familiarity with the symptomology of infectious and diarrheal disease, micronutrient deficiency, etc., and with the notion that these are the afflictions which allopathic medicine was designed to treat, is less than perfect among either the laity or the monks. As critical links in the complex local medical system, however, the lama and dawa who perform $m u$ tu may be the most productive points of contact for health educators who aim to provide information to clients making critical treatment choices. At the more general policy level, it is suggested that health education policy-makers seeking credible local sources of information dissemination would profit by identifying and targeting this and other similar channels of communication in indigenous health systems.

A virtue of this approach is that it fits within the definition of culturally appropriate interventions. As observers of Nepalese health behavior have remarked, the imposition of alien medical priorities upon a traditional people (who may consider themselves to be the best judges of their own health needs) most often proves counterproductive [9]. $M u t u$, however, is commissioned only when a need for guidance is perceived by the client. The commissioning of $m u t u$, therefore, constitutes a form of selfselection by the client for exposure to additional information. The monk, in this case, is providing a requested service. In this way, information may be introduced without the likelihood of resistance which top-down impositions of foreign cultural and healthrelated values often provokes. What is more, health education through the vehicle of $m u t u$ is compatible with the continued acceptance and promulgation of traditional healing practices for certain complaints such as emotional difficulties, disruptions in social relations, and the host of misfortunes that are normally encompassed by the concept of illness in northern Nepal. Thus, it does not constitute an attempt to 'replace' indigenous cultural values or concepts with alien systems of explanation.

To what extent are these conclusions applicable to a larger cultural area or to health education more generally? The institution of $m u t u$, at least in this application, may be unique to Thak Khola. Nevertheless, it constitutes a specific example of what may be a more generally prevalent phenomenon: an indigenous method of coordinating patterns of resort in a medically pluralistic system. The co-existence of two or more ritual traditions in other areas of Nepal has been widely documented [30-32]. The long-term interaction between healing alternatives suggests that some structure or system of coordination-of which mutu is one instance-is likely to have emerged in many areas.

This analysis has particular relevance to the Nepal hills, where a variety of indigenous traditions has co-existed for generations. In areas which are pluralistic due to recent immigration (such as Nepal's Terai region), however, there may have been insufficient time for linkages of referral to develop.
If so, then exclusionary competition between alternatives (including the allopathic alternative) may characterize their interaction. If the common South Asian cultural pattern of aggregation persists in areas of recent influx, however, it may be argued that time will bring about a mutual accommodation between these medical traditions instead of a simple effacement of indigenous by introduced Western beliefs and technologies. If so, then as Blustain has proposed, "The problem facing the public health worker is one of finding the means of integrating western ideas into the village system" $[1$, p. 103]. This review of the institution of mutu suggests that health planners and health educators may find it worthwhile to investigate indigenous referral systems as a means of securing the position of allopathic medicine within Nepal's health care network.

\section{REFERENCES}

1. Blustain H. S. Levels of medicine in a central Nepali village. Contrib. Nepal. Stud. 3, 83-105, 1976.

2. Durkin-Longley M. Multiple therapeutic use in urban Nepal. Soc. Sci. Med. 19, 867-872, 1984.

3. Stone L. Concepts of illness and curing in a central Nepal village. Contrib. Nepal. Stud. 3, 55-80, 1976.

4. Streefland $\mathrm{P}$. The frontier of modern western medicine. Soc. Sci. Med. 20, 1151-1159, 1985.

5. Achard T. Primary Health Care in the Hills of Nepal. Integrated Hill Development Project. His Majesty's Government of Nepal/Swiss Association for Technical Assistance. Shahayogi Press, Kathmandu, 1983.

6. Okada F. E. Notes on two shaman-curers in Kathmandu. Contrib. Nepal. Stud. 3, 107-112, 1976.

7. Oswald I. H. Are traditional healers the solution to the failures of primary health care in rural Nepal? Soc. Sci. Med. 17, 255-257, 1983.

8. Shrestha R. M. and Lediard M. Faith Healers: A Force for Change. Educational Enterprises, Kathmandu, 1980.

9. Stone L. Primary health care for whom? Village perspectives from Nepal. Soc. Sci. Med. 22, 293-302, 1986.

10. Dhakal R., Graham-Jones S, and Lockett G. Traditional Healers and Primary Health Care in Nepal. SCF-UK, Kathmandu, 1986.

11. Foster G. Medical anthropology and international health planning. In Health and the Human Condition: Perspectives on Medical Anthropology (Edited by Logan M. H. and Hunt E. E.), pp. 301-313. Duxbury Press, North Scituate, Mass., 1978.

12. Nichter M. Patterns of resort in the use of therapy systems and their significance for health planning in South Asia. Med. Anthrop. 2, 29-56, 1978.

13. Beals A. R. Strategies of resort to curers in South India. In Asian Medical Systems: A Comparative Study (Edited by Leslie C.), pp. 184-200. University of California Press, Berkeley, Calif., 1976.

14. Dumont L. Homo Hierarchicus: The Caste System and its Implications. University of Chicago Press, Chicago, Ill., 1970.

15. Jackson D. P. Notes on the history of $S e-R i b$ and nearby places in the Upper Kali Gandaki Valley. Kailash 6, 195-227, 1978.

16. Vinding $M$. The Thakalis as Buddhists: a closer look at their death ceremonies. Kailash 9, 291-318, 1982.

17. Bista D. B. The political innovators of Upper KaliGandaki. Man 6, 52-60, 1971.

18. Fürer-Haimendorf C. von. Himalavan Traders: Life in Highland Nepal. Murray, London, 1975.

19. Vinding $M$. Marriage systems of the Thakalis and related groups of the Bodish section of Sino-Tibetan speaking peoples. Folk 21/22, 325-345, 1979/80. 
20. Kawakita J. Peoples of Nepal Himalaya. In Scientific Results of the Japanese Expedition to the Nepal Himalaya (Edited by Kihara H. L.). Vol. III. Flora and Fauna Research Society, Kyoto University, Kyoto, 1957.

21. Bista D. B. The People of Nepal, 3rd edn. Ratna Pastak Bhandar, Kathmandu, 1976.

22. Parker B. The spirit of wealth: culture of entrepreneurship among the Thakali of Nepal. Ph.D. dissertation, University of Michigan, 1985.

23. Maru R. M. Health manpower strategies for rural health services in India and China. Soc. Sci. Med. 11. 535-547, 1977.

24. Ortner S. B. Sherpas Through Their Rituals. Cambridge University Press, 1978.

25. Trungpa C. Rinpoche. Some aspects of Pön. In Himalayan Anthropology (Edited by Fisher J.). Mouton, The Hague, 1978.

26. Manzardo A. To be kings of the North: adaptation and impression management in the Thakali of Western Nepal. Ph.D. dissertation, University of Wisconsin at Madison, 1978.

27. Jest C. Encounters with intercessors in Nepal. In Spirit Possession in the Nepal Himalayas (Edited by Hitchcock
J. R. and Jones R. L.), pp. 294-306. Vikas, New Delhi, 1976.

28. Burghart R. The Tisiyahi Klinik: a Nepalase medical centre in an intercultural field of relations. Soc. Sci. Med. 18, 589-598. 1984.

29. The gelong lama might be expected to object to jhankri practice because in the lowland areas of Nepal, animal sacrifice (abhorrent to Tibetan Buddhists) figures in their rites. In Marpha, however, the lama are suffciently powerful to have prohibited animal sacrifice within the village gates. Village jhankri thus limit themsleves to the rites described. The ayalama does sacrifice animals outside the village, and the leading lama has attempted to persuade him to transform these rites into presentations of rice and incense. Local opinion, however, was deeply divided on this point at the time of the study.

30. Messerschmidt D. The Gurungs of Nepal: Conflict and Change in a Village Society. Aris \& Phillips, Warminster, 1976.

31. Jones R. L. Sanskritization in eastern Nepal. Ethnology 15, 63-75, 1976

32. Holmberg D. Shamanic soundings: femaleness in the Tamang ritual structure. Signs 9, 40-58, 1983. 